Helge Braun, Roland Döhrn, Michael Krause, Martin Micheli and Torsten Schmidt*

\title{
Macroeconomic Long-Run Effects of the German Minimum Wage when Labor Markets are Frictional
}

https://doi.org/10.1515/jbnst-2018-0080

Received September 29, 2018; revised July 01, 2019; accepted July 12, 2019

Abstract: This paper analyzes the introduction of the German minimum wage in 2015 in a structural model geared to quantitatively assess its long-run economic effects. We first employ a simple neoclassic model where wages equal their marginal product, then extend this model to two sector economy, and finally introduce search and matching frictions. Even though all model variants remain highly stylized, they yield quantitative insights on the importance of different mechanisms and channels through which minimum wages affect outcomes in the long run. In this framework, the minimum wage has a strong negative effect on employment. When sectors are differently affected by the minimum wage, sectoral relative price changes play an important quantitative role. Other labor market policies and institutions are important for the transmission of minimum wage policy on labor market market outcomes.

Keywords: minimum wage, unemployment, Germany

JEL Classification: E24, J38, J63

\section{Introduction}

On January 1st, 2015, the German federal government introduced a statutory minimum wage. The introduction was accompanied by a fierce debate about its

\footnotetext{
*Corresponding author: Torsten Schmidt, RWI - Leibniz-Institut for Economic Research, Hohenzollernstr. 1-3, 45128 Essen, Germany, E-mail: torsten.schmidt@rwi-essen.de Helge Braun, RGS Econ and RWI - Leibniz-Institute for Economic Research, Hohenzollernstr. 1-3, 45128 Essen, Germany, E-mail: Helge.Braun@rwi-essen.de

Roland Döhrn, RWI - Leibniz-Institute for Economic Research, Hohenzollernstr. 1-3, 45128 Essen, Germany, E-mail: roland.dohrn@rwi-essen.de Michael Krause, University of Cologne, Center for Macroeconomic Research (CMR), Albertus-Magnus-Platz, 50923 Cologne, Germany, E-mail: michael.krause@wiso.uni-koeln.de Martin Micheli, RWI - Leibniz-Institute for Economic Research, Hohenzollernstr. 1-3, 45128 Essen, Germany, E-mail: martin.micheli@rwi-essen.de
} 
economic effects, reflecting the controversy in the economic literature. ${ }^{1}$ The German Council of Economic Experts stressed potential negative employment effects for low income earners (SVR 2013: TZ 515-521). The German government emphasized positive effects due to higher wages and considered employment effects to be of minor importance (BMWI 2014).

By now, almost four years since the introduction of the minimum wage in Germany, there have not been any apparent negative effects on the German labor market. The minimum wage had a positive effect on hourly wages (Mindestlohnkommission 2016), but there is no evidence of higher incomes. ${ }^{2}$ The minimum wage went, not surprisingly, hand in hand with a reduction of mini jobs, which are not subject to social security contributions, and an increase in employment subject to social security (Gemeinschaftsdiagnose 2014). It is, however, unclear whether this can be linked causally to the introduction of minimum wages. Employing an inter-regional comparison, Garloff (2016) and Ahlfeldt et al. (2018) do not find evidence for disemployment effects using inter-regional variation in the minimum wage's marginal impact. Garloff (2016) further documents that employment requiring the payment of social security contributions increased strongest in regions where the number of mini jobs decreased the most. Bossler and Gerner (2016), on the other hand, find mild disemployment effects. However, all this evidence investigates the introduction of minimum wage in Germany during an economic boom. ${ }^{3}$

This paper investigates long-run general equilibrium effects of the German minimum wage. Our main focus are minimum wage effects in the long run, which allows us to use stylized models that abstract form short-run frictions. Starting points are simple neoclassic one-sector and two-sector models, where wages

1 This dissent is mainly about the employment effect of minimum wages and has its root in differing views regarding the appropriate control group to which the evolution of employment after a minimum wage hike is compared to. Studies comparing employment in two geographically close regions, where only one region saw a minimum wage change, typically do not find disemployment effects (Dube et al. 2010, 2016; Allegretto et al. 2017). Studies that use minimum wage variation at the broader state level typically find a significant decrease in teen employment (Neumark et al. 2014a,b). For a survey of the recent literature, see Neumark (2017).

2 With respect to income effects of minimum wages, one has to also take into account that higher labor income due to minimum wages may reduce transfers or affect hours worked (Knabe et al. 2014: 31). Reducing transfer dependence might be a policy goal, even though this does not result in higher incomes. This substitution of transfers took place after the introduction of minimum wages in Germany (Mindestlohnkommission 2016; Schmitz 2017).

3 Vom Berge and Frings (2017) evaluate the introduction of a sectoral minimum wage for the German construction sector, which was introduced in the late 1990s when economic conditions were substantially worse. They do not find effects for West Germany, but negative employment effects in East Germany. 
equal the marginal product of labor. There is, however, a consensus among labor economists that these neoclassic models are an overly simplistic representation of the economy. Wages are typically found to be below the marginal product of labor. Hirsch et al. (2010) and Bachmann and Frings (2017) show this for the German labor market by estimating the labor supply elasticity to the firm. We therefore augment the one- and two- sector model with search and matching frictions and wage bargaining, such that wages can fall below the marginal product of labor. ${ }^{4}$

We calibrate the different models to fit the German economy prior to the minimum wage introduction. For quantitative simulations, we calibrate the introduction of the minimum wage as a shock that affects a number of individuals and increases the wage of affected individuals of a magnitude similar to what was observed in Germany. After the initial shock, the real minimum wage remains constant. We then show how different parameters values influence the response of the labor market and the macroeconomy. In most calibrations, employment effects in the search and matching framework are comparable to the ones in the neoclassic model.

Of course, minimum wage effects have been studied in a search and matching framework before. Joseph et al. (2004) shows the effect a minimum wage increase on macroeconomic variables. Flinn (2006) emphasized the importance of bargaining power for the transmission of minimum wage policies. Brown et al. (2014) show that the level of the minimum wage crucially affects employment effects of minimum wages. In their model, job acceptance of workers and the job offers of firms are modeled separately, and wages are determined after the employment decision has been made.

We contribute to the literature by comparing minimum wage effects in models with a neoclassic labor market to the ones in a more realistic search and matching framework in coherent calibrations. We find that minimum wage effects in neoclassic and search and matching framework are very similar in the long run. We also highlight which processes are driving disemployment effects by showing which parameters are driving the deviations from the simple neoclassic model.

The paper proceeds as follows. Section 2 presents the simple neoclassic model without labor market frictions. We analyze a minimum wage effects in a one-sector version and in a two-sector version. Section 3 introduces labor market frictions by implementing a search and matching structure. We discuss the effect of the introduction of a minimum wage for different parameter constellations. We then extend that model to a two-sector structure and again discuss differences between the two model variants. Section 4 concludes.

4 Even though we allow labor supply to be somewhat elastic, the model is not monopsonistic in the sense of Manning (2003) as wages are the result of bargaining and not set by employers. 


\section{The model}

This section presents the two simple neoclassical benchmark models, which we use to start our analysis of the effects of the introduction of a minimum wage. We begin with the one-sector model in Section 2.1, while Section 2.2 extends the model by introducing a two-sector structure in the production process. One sector uses high skilled labor and the other sector produces with low skilled labor.

\subsection{A simple Neoclassic model}

The simple one sector economy consists of three agents: households, so-called labor bundlers, and final good firms.

\subsubsection{Households}

There is a continuum of households with unit mass. Each household in turn consists of a continuum of household members. Each household member receives one job offer at the beginning of the period. Household members then draw from a uniform distribution to determine idiosyncratic labor productivity for the respective period. ${ }^{5}$ Household members insure each other against the different realizations of productivity. The representative household maximizes expected discounted utility from consumption $c$ :

$$
E_{0} \sum_{t=0}^{\infty} \beta^{t} \log \left(c_{t}\right)
$$

where $0<\beta<1$ represents the discount factor. Households face the budget constraint

$$
c_{t}+x_{t}=\int_{i} w_{i t} d i+r_{t}^{k} k_{t-1}+\Pi_{t}^{B}+\Pi_{t}^{P} .
$$

Consumption and investment $x$ in working capital $k$ are restricted by household income. Household income consists of labor income, with the wage $w_{i}$ and capital income from renting out capital at the rate $r_{t}^{k} . \Pi_{t}^{B}$ and $\Pi_{t}^{P}$ represent profits of the labor bundlers $(B)$ and of final good firms $(P)$, both described below.

5 The process determining individual productivity is similar to match specific productivity in a search model. 
The capital stock follows the law of motion

$$
k_{t}=x_{t}+(1-\delta) k_{t-1}
$$

where $\delta$ is the depreciation rate of capital. The Euler equation resulting from solving the households optimisation problem says that marginal utility of consumption must equal the discounted marginal utility of the return on investment, or

$$
c_{t}^{-1}=\beta E_{t}\left[c_{t+1}^{-1}\left(1-\delta+r_{t+1}^{k}\right)\right]
$$

\subsubsection{Labor bundlers}

The notion of labor bundlers is introduced to simplify the aggregation of labor. They combine labor input by households to standardizes units, which they sell to final good firms. In doing so they maximize profits

$$
\Pi_{t}^{B}=d_{t} g_{t}-\int w_{i t} d i
$$

with the price $d$ of a standardized unit of labor $g$. Idiosyncratic labor productivities $a_{i}$ are distributed according to a distribution $F(a)$ and combined linearly to form the standardized labor units $g$.

$$
g_{t}=\int a_{i t} d i
$$

Each worker is paid his or her idiosyncratic marginal productivities:

$$
w_{i t}=d_{t} a_{i t}
$$

\subsubsection{Final good firms}

Final good firms use the input factors capital and standardized labor to produce final goods. They maximize profit

$$
\Pi_{t}^{P}=y_{t}-r_{t}^{k} k_{t-1}-d_{t} g_{t}
$$

subject to the production technology

$$
y_{t}=k_{t-1}^{\alpha} g_{t}^{1-\alpha} .
$$


In equilibrium, the cost of using an additional unit of factor inputs equals its return, which determines factor prices:

$$
d_{t}=(1-\alpha) \frac{y_{t}}{g_{t}}
$$

and

$$
r_{t}^{k}=\alpha \frac{y_{t}}{k_{t-1}}
$$

\subsubsection{Equilibrium}

The equilibrium of the economy can be described by the system of eqs. (4), (6), (7), (9), (10), (11), an assumption with regard to the distribution of individual productivity $F(a)$ and the resource constraint

$$
c_{t}+k_{t}=y_{t}+(1-\delta) k_{t-1}
$$

which combines the budget constraints (2), (5), (8) and the law of motion for capital (3).

\subsubsection{Calibration}

Before simulating the introduction of a minimum wage, we have to make assumptions with regard to the three parameters $\alpha, \beta$, and $\delta$ as well as the distribution of match specific productivity $F(a)$. We calibrate the model on a quarterly frequency. Our parameter choices are guided by the literature.

The parameter $\alpha$ determines labor and capital shares. Similar to Joseph et al. (2004), we set $\alpha=0.33$, which implies a labor share of $2 / 3$. The depreciation rate $\delta$ is set to 0.025 , which is also similar to Joseph et al. (2004). The value implies an annual depreciation rate of about $10 \%$. $\beta$ determines the real interest rate. We use the value 0.99 , resulting in a steady state real interest rate of $4 \%$.

With regard to the distribution of match specific productivities, we have to assume a distribution function. The literature typically assumes either a lognormal or a uniform distribution. The use of a lognormal distribution is typically motivated by a lognormal distributed of wages in the US, e. g. Flinn (2006). The uniform distribution is computationally less demanding and has originally been proposed by Mortensen and Pissarides (1999) and used e.g. by Joseph et al. (2004). For Germany, Krause and Uhlig (2012) assume a uniform distribution of match specific productivities for low skilled workers. The empirical distribution 
of low income earners in the year 2014 seems to support the hypothesis of a uniform distribution (Mindestlohnkommission 2016: 51, figure 5). We therefore follow Krause and Uhlig (2012) and assume a uniform distribution. We set $E\left(a_{i t}\right)=\bar{a}=1$. The density function is

$$
f\left(a_{i}\right)= \begin{cases}\frac{1}{2 \sigma} & \text { for } \bar{a}-\sigma \leq a_{i} \leq \bar{a}+\sigma \\ 0 & \text { otherwise }\end{cases}
$$

We calibrate $\sigma$ such that the introduction of a minimum wage, which is $18 \%$ above the average wage of potential minimum wage earners, would affect $6 \%$ of all employees in the undistorted steady state. These values are motivated by the observed lower end of the wage distribution in 2014 (Statistisches Bundesamt 2016). This results in a value of 0.79 for $\sigma$.

\subsubsection{Introduction of a minimum wage}

In the equilibrium of the model without distortions, all individuals receive an offer to work. The wage equals the marginal product of labor, which is determined by individual productivity. As there is no wage floor, all individuals are working. After introducing a minimum wage, individuals whose wage is below the minimum wage will not be working. Employers have no incentive to hire these workers. After the initial introduction, real minimum wages remain constant. ${ }^{6}$

\subsection{Simple two-sector model}

In the two-sector model, there is one sector employing high qualified $H$ and one sector employing low qualified $L$ employees. Correspondingly, households consist of high and low qualified individuals, there are two types of labor bundlers, and two types of final good producers and, additionally, a final good bundler. The latter aggregates the two sectoral outputs into one final good.

\subsubsection{Households}

The representative household again consists of a continuum of members. A share $N^{H}$ is high qualified, and a share $N^{L}=1-N^{H}$ is low qualified. All individuals

6 By assuming the minimum wage being constant in real terms, we prevent them from ceasing to be binding over time. While there is no explicit indexation of the minimum wage in German, the Minimum Wage Commission bi-annually assesses the appropriateness of its level. 
inelastically supply one unit of labor. Similar to Section 2.1, households maximize discounted utility (1) subject to a budget constraint. The budget constraint in the two-sector model reads

$$
c_{t}+K_{t}=\int_{i} w_{i t}^{H} d i N^{H}+\int_{i} w_{i t}^{L} d i N^{L}+r_{t}^{K H} K_{t}^{H}+r_{t}^{K L} K_{t}^{L}+(1-\delta) K_{t-1}+\Pi_{t} .
$$

where $w_{i}^{H}$ and $w_{i}^{L}$ are the individual real wages for high and low qualified individuals. $r^{K H}$ and $r^{K L}$ are the respective prices for renting capital. All firms are owned by households, which receive profits $\Pi_{t} . K$ is the aggregate stock of working capital. Capital is freely mobile between the two sectors. $K^{H}$ is the capital stock used in the high skilled sector, $K^{L}$ is the capital stock in the low skilled sector.

$$
K_{t}^{H}+K_{t}^{L}=K_{t-1}
$$

Utility maximization yields an Euler equation as well as arbitrage condition for the interest rates.

$$
\begin{gathered}
c_{t}^{-1}=\beta E_{t}\left[c_{t+1}^{-1}\left(1-\delta+r_{t+1}^{k H}\right)\right] \\
r_{t}^{K H}=r_{t}^{K L} .
\end{gathered}
$$

\subsubsection{Labor bundlers}

Profit maximization for labor bundlers of high and low qualified labor are identical, and identical to the one of Section (2.1.2). They maximize profits $\Pi_{t}^{j B}=$ $d_{t}^{j} g_{t}^{j}-\int w_{i t}^{j} d i$ subject to the production technology $g_{t}^{j}=\int a_{i t}^{j} d F\left(a^{j}\right)$ with $j \in\{H, L\}$. This yields the prices for input factors

$$
w_{i t}^{j}=d_{t}^{j} a_{i t}^{j}
$$

\subsubsection{Final good firms}

Final good firms face the same maximization problem as in Section 2.1.3. They maximize profit $\Pi_{t}^{j P}=\frac{P_{t}^{j}}{P_{t}} y_{t}^{j}-r_{t}^{K j} K_{t}^{j}-d_{t}^{j} g_{t}^{j}$ subject to the production technology $y_{t}^{j}=\left(K_{t}^{j}\right)^{\alpha}\left(g_{t}^{j}\right)^{1-\alpha}$ for $j \in\{H, L\} . P_{t}^{j}$ represents the price of the final good in a respective sector and $P_{t}$ is the aggregate price level. This setup results in the first order conditions 


$$
\begin{gathered}
d_{t}^{j}=\frac{P_{t}^{j}}{P_{t}}(1-\alpha) \frac{y_{t}^{j}}{g_{t}^{j}} \\
r_{t}^{K j}=\frac{P_{t}^{j}}{P_{t}} \alpha \frac{y_{t}^{j}}{K_{t}^{j}} .
\end{gathered}
$$

\subsubsection{Final good bundlers}

Final good bundlers combine final goods, produced with high and low skilled labor, to a bundle of final good they sell to households. They minimize costs $P_{t}^{H} y_{t}^{H}+P_{t}^{L} y_{t}^{L}$ subject to the production technology

$$
y_{t}=\left(\left(\gamma^{H}\right)^{\frac{1}{\eta}}\left(y_{t}^{H}\right)^{\frac{\eta-1}{\eta}}+\left(\gamma^{L}\right)^{\frac{1}{\eta}}\left(y_{t}^{L}\right)^{\frac{\eta-1}{\eta}}\right)^{\frac{\eta}{\eta-1}},
$$

with $\gamma^{H}=\gamma$ and $\gamma^{L}=1-\gamma$, the relative weight of the respective final good in the bundling process, and the elasticity of substitution $\eta$. The resulting demand for final goods are

$$
y_{t}^{j}=\left(\frac{P_{t}^{j}}{P_{t}}\right)^{-\eta} \gamma^{j} Y_{t}
$$

and the price level is

$$
P_{t}=\left[(1-\gamma)\left(P_{t}^{H}\right)^{1-\eta}+\gamma\left(P_{t}^{L}\right)^{1-\eta}\right]^{\frac{1}{1-\eta}} .
$$

\subsubsection{Equilibrium}

The equilibrium of the economy can be described by the Euler eq. (16), the interest parity (17), labor demand (18), the production functions of labor bundlers $g_{t}^{j}=$ $\int a_{i t}^{j} d i$, the four prices of input factors (19) and (20), the production functions of final good firms $y_{t}^{j}=\left(K_{t}^{j}\right)^{\alpha}\left(g_{t}^{j}\right)^{1-\alpha}$, the demand functions for final goods (22) and final good bundlers (21), the resource constraint $y_{t}=c_{t}+k_{t}-(1-\delta) k_{t-1}$, the law of motion for capital (15), as well as assumptions concerning the distribution of individual productivity in the two sectors.

With regard to the distribution of productivity, we assume - corresponding to the simple neoclassic model - a uniform distribution. The average wage in the 
initial steady state results from integration over productivity specific wages in the respective sector $\int_{i} w_{i t}^{j} d i=d_{t}^{j} \int_{i} a_{i t}^{j} d F(a)=d_{t}^{j} \bar{a}_{t}^{j}=\bar{w}_{t}^{j}$.

\subsubsection{Calibration}

The two sector model entails eight parameters we need to calibrate: $\alpha, \beta, \delta, \eta, \gamma^{H}, \gamma^{L}, N^{H}$ and $N^{L}$. For $\alpha, \beta$ and $\delta$ we use the same values as in the one sector model (Section 2.1.5). We calibrate $\sigma$ similar to the procedure described in Section 2.1.5. In the initial steady state, $6 \%$ of all working individuals should exhibit a wage lower than the minimum wage and the minimum wage should be $18 \%$ above the average wage of these $6 \%$. $\sigma$ is set to 0.38 in the low skilled sector. For the high qualified sector, we assume that the minimum wage is not binding due to the higher productivity.

We have to calibrate 5 further parameters. The shares of high $\left(N^{H}\right)$ and low skilled $\left(N^{L}\right)$ workers, the weights of the two products in the production function of final good bundlers $\left(\gamma^{H}, \gamma^{L}\right)$ as well as the elasticity of substitution of the two types of goods in the bundling process $(\eta)$. To calibrate these parameters, we devide the German economy in a high and a low skilled sector. We thereby rely on the classification of economic activities (WZ 2008) as well as on the minimum wage commission, which identified the 20 branches that are potentially most affected by the minimum wage introduction (Mindestlohnkommission 2016: Table 4 on page 43). We match these 20 branches to branches of the German economy according to the system of national accounts (Reihe 1.4 der Fachserie 18), which is slightly broader. If there is only a superordinate branch in the national accounts, we label the entire branch as minimum wage branch if more than half of all employees were employed in the potentially highly affected branch. ${ }^{7}$

\footnotetext{
7 According to this procedure, highly affected branches are: 'Fishing and aquaculture', 'Retail trade, except of motor vehicles and motorcycles', 'Postal and courier activities', 'Accommodation and food service activities', 'Publishing activities', 'Advertising and market research', 'Rental and leasing activities', 'Sports activities and amusement and recreation activities', 'Repair of computers and personal and household goods' and 'Activities of households as employers; unidentified undifferentiated goods- and services-producing activities of households for own use'. The four largest branches with respect to the number of employed individuals in 2014 are: 'Retail trade, except of motor vehicles and motorcycles', 'Postal and courier activities', 'Accommodation and food service activities', 'Activities of households as employers; unidentified undifferentiated goods- and services-producing activities of households for own use', which make up for about 88 percent of employment in minimum wage branches. These services are, however, hard to substitute for by internationally traded goods in case of minimum wage driven price increases for these services. We therefore argue that abstracting from substitution by internationally trades goods should be less of an issue.
} 
To calibrate employment shares, we use the time period from 1991 to 2014. In this period, the ratio of employees in not affected to highly affected sectors was 5:1. This results in the relative employment shares $N^{H}=0.83$ and $N^{L}=0.17$. We calibrate $\gamma$ (with $\gamma^{L}=\gamma$ and $\gamma^{H}=1-\gamma$ ) using relative value added in the two sectors. Relative nominal value added $\frac{P^{H} y^{H}}{P^{L} y^{L}}$ in the two sectors was about 9 in the respective period. We set $\eta$ using the demand functions for final goods (22). Rewriting this equation yields an expression linking relative price changes to relative demand.

$$
\log \left(\frac{y_{t}^{L}}{y_{t}^{H}}\right)=-\eta \log \left(\frac{p_{t}^{L}}{p_{t}^{H}}\right)+\log \left(\frac{\gamma}{1-\gamma}\right)
$$

We calculate time series for real value added and deflators in the two sectors and estimate (24). For the time period from 1991 to 2014, the estimate for $\hat{\eta}$ is 0.95 with a standard error of $0.2580 .^{8}$

\subsection{Results}

We present the simulation results for the effects after 2, 5, and 10 years in Table $1 .{ }^{9}$ All values represent deviations of the respective variables from the initial steady state. As this model abstracts from frictions, as e. g. nominal frictions which are well documented in the literature (Bils/Klenow 2004; Dhyne et al. 2006), effects in the short and medium term should be interpreted with caution. We therefore take the simulation results as indicative of long-run effects, which might occur after the economy has adjusted to the new steady state.

Column (1) shows the effects of the minimum wage introduction in the simple one sector model of Section 2.1. A binding minimum wage makes employing individuals at the lower end of the production distribution unprofitable. This results in a decline of labor demand. As the minimum wage forces the least productive individuals out of employment, this mechanically increases average labor productivity. Due to decreasing returns to scale and working capital being predetermined, the capital stock is well above its new steady state level when the minimum wage is introduced. Therefore, investment activity is subdued during the transition period. Consumption only declines gradually. Lower investment

8 The estimated coefficient is sensitive to the sample period. Employing a sub-sample analysis, the coefficient has become smaller in recent years.

9 We use the software package Dynare to simulate the model (Adjemian et al. 2011). 
Table 1: Simulation results, simple model.

\begin{tabular}{|c|c|c|}
\hline & $\begin{array}{r}\text { One sector model } \\
\text { (1) }\end{array}$ & $\begin{array}{r}\text { Two sector model } \\
\text { (2) }\end{array}$ \\
\hline \multicolumn{3}{|l|}{ GDP } \\
\hline 2 years & -1.12 & -1.13 \\
\hline 5 years & -1.26 & -1.27 \\
\hline 10years & -1.39 & -1.40 \\
\hline \multicolumn{3}{|c|}{ Consumption } \\
\hline 2 years & -0.82 & -0.83 \\
\hline 5 years & -1.06 & -1.08 \\
\hline 10years & -1.30 & -1.32 \\
\hline \multicolumn{3}{|c|}{ Investment } \\
\hline 2 years & -1.99 & -2.11 \\
\hline 5 years & -1.83 & -1.90 \\
\hline 10years & -1.67 & -1.70 \\
\hline \multicolumn{3}{|l|}{ Savings } \\
\hline 2 years & -1.99 & -2.11 \\
\hline 5 years & -1.83 & -1.90 \\
\hline 10years & -1.67 & -1.70 \\
\hline \multicolumn{3}{|c|}{ Gross wages and salary } \\
\hline 2 years & -1.12 & -1.13 \\
\hline 5 years & -1.26 & -1.27 \\
\hline 10years & -1.39 & -1.40 \\
\hline \multicolumn{3}{|c|}{ Corporate and investment income } \\
\hline 2 years & -1.12 & -1.13 \\
\hline 5 years & -1.26 & -1.27 \\
\hline 10years & -1.39 & -1.40 \\
\hline \multicolumn{3}{|c|}{ Average productivity } \\
\hline 2 years & 4.59 & 1.05 \\
\hline 5 years & 4.61 & 1.05 \\
\hline 10years & 4.63 & 1.06 \\
\hline \multicolumn{3}{|c|}{ Hours worked, employment } \\
\hline 2 years & -5.83 & -3.35 \\
\hline 5 years & -5.85 & -3.37 \\
\hline 10years & -5.88 & -3.38 \\
\hline
\end{tabular}

Deviations from a non-minimum wage steady state in percent. Authors' calculations.

reduces the requirement for savings, which necessitates only small consumption sacrifices. Aggregate real economic activity declines, which negatively affects incomes.

Column (2) presents the results in the two-sector model. The introduction of a minimum wage lowers employment. However, this decline is substantially 
smaller than in the one-sector model. Lower production in the low skilled sector increases relative prices for this sector's output, which ceteris paribus increases the productivity threshold in the low skilled sector. The increase in average productivity is less pronounced as the minimum wage destroys less of the least productive jobs compared to the ones ector model.

\section{Effects of the minimum wage in a canonical search and matching framework}

In an extension of Section 2.1, we use a canonical search and matching model as formulated by Joseph et al. (2004) to analyze the effects of a minimum wage in a setting with frictional labor markets. This type of model is frequently used in the literature on macroeconomic effects of labor market policies (Krause/Uhlig 2012; Balleer et al. 2016) and allows us to incorporate the effects of a minimum wage on the search behavior of workers, the vacancy creation of firms, and the destruction of existing employment relationships. Moreover, it can account for market power on both sides of the labor market and lends itself to the joint analysis of minimum wages along with other labor market policies, such as unemployment benefits and firing costs. In principle, these aspects may significantly alter the impact of minimum wages. For example, the presence of frictions partially detaches wages from workers' marginal revenue products, leaving room for wage changes that do not induce unemployment. Furthermore, in a frictional labor market, minimum wages may increase workers' search effort, counteracting negative employment effects. The quantitative analysis assesses the role of these additional mechanisms in a sensitivity analysis.

\subsection{The Model}

We restrict our analysis to steady states and interior solutions, suppressing time indices in the notation. The aggregate structure of the model is identical to Section 2.1. In particular, production of the final good, consumption, and capital accumulation follow as described in 2.1.1 and 2.1.3. The labor market described below replaces the modeling of the labor market described in 2.1.2. Intermediate goods are now produced by firm-worker matches with fixed labor input (hours), normalized to 1. Frictions in the labor market imply that, at any given point in time, not all workers are employed. Some are currently unemployed and searching for a job. (We abstract from on-the-job search.) This process takes time. Similarly, workers currently employed with a firm stay with the firm in the next 
period and are subject to idiosyncratic productivity shocks which may lead to job loss and their return to the pool of unemployed and searching workers. Firms, on the other hand, are also subject to frictions in filling vacancies. They expend resources to post job openings and finding a suitable worker takes time.

\subsubsection{Matching Function, Labor Market Flows}

Contacts between searching, unemployed workers and job vacancies created by firms arise according to a standard constant returns to scale matching function $M(S U, V)=\bar{m}(S U)^{1-\lambda} V^{\lambda}$. This matching function captures the idea of frictions in the labor market. $V$ denotes vacancies, $U$ the mass of unemployed workers, and $S$ the search intensity of these unemployed workers. The parameters $\bar{m}>0$ and $0<\lambda<1$ are the matching efficiency and the elasticity of the matching function with respect to vacancies, respectively. Accordingly, a searching worker contacts a vacancy at rate (probability) $M(S U, V) / U .^{10}$ The probability that a vacancy contacts a searching worker in a given period is $M(S U, V) / V$.

Contacts generated via the matching function do not, however, necessarily lead to productive firm-worker matches in the following period, because the (potential) match is subject to an idiosyncratic, match-specific productivity $a$. This match-specific productivity, which is effective for one period, is drawn independently at the beginning of each period by all new and pre-existing matches, new and preexisting matches from the previous period, from the distribution $F$, with support $\left[a_{\min }, a_{\max }\right]$. As described below, a productive match is only realized from an initial contact if this idiosyncratic productivity is larger than a threshold value, denoted by $R^{0}$, where the superscript 0 denotes newly formed matches. ${ }^{11}$ Hence, a fraction $F\left(R^{0}\right)$ of initial contacts does not lead to matches, and the job finding probability of searching workers is $\left(1-F\left(R^{0}\right)\right) M(S U, V) / U$, which is the inverse of average unemployment duration. Similarly, the vacancy filling probability is $\left(1-F\left(R^{0}\right)\right) M(S U, V) / V$.

$N^{0}$ denotes the mass of newly created employment relationships, with $N^{0}=$ $\left(1-F\left(R^{0}\right)\right) M(S U, V) . N^{1}$ denotes the mass of employment relationships that had already produced in the previous period. The total number of employment relationships is hence $N=N^{0}+N^{1}$. Note that we need to distinguish between pre-existing and newly formed employment relationships due to the assumption that the latter are subject to firing costs, whereas the former are not (see below).

10 In the quantitative simulation experiments below, this and all other rates are between zero and one subsequently denoted as probabilities.

11 The model calibration will involve $R^{0}>a^{\text {min }}$. 
The total mass of workers is normalized to one, such that $U=1-N$. The separation rate follows from a firm decision described in more detail below. Firms will terminate all matches with an idiosyncratic productivity drawn at the beginning of a period that falls below a threshold $R^{1}$. Hence, the separation rate is $F\left(R^{1}\right){ }^{12}$

The mass of employed workers follows from the labor market flow relationship, equating in- and outflows,

$$
\left(1-F\left(R^{0}\right)\right) M(S(1-N), V)=F\left(R^{1}\right) N .
$$

The mass of employed workers is increasing in the job finding rate and decreasing in the separation rate. In the following, decisions pertaining to separation $\left(\left(R^{0}, R^{1}\right)\right)$, vacancy creation $((V))$ and search intensity $(S)$ are described. Subsequently, we describe how wages are determined, which in turn influences these decisions.

\subsubsection{Vacancy Creation and Separation Decision}

The firm value of a pre-existing match with match-specific productivity $a$ is denoted with $\tilde{W}^{F, 1}(a)$ and satisfies

$$
\tilde{W}^{F, 1}(a)=a d-w^{1}(a)+\beta\left(\int_{a_{\min }}^{a_{\max }} \max \left[\tilde{W}^{F, 1}(z), \tilde{V}-f\right] d F(z)\right),
$$

where $d$ is the price of a standardized unit of labor and $a d$ is revenue generated by the match, measured in units of the final good. The firm's current wage costs are $w^{1}(a)$, which will either be equal to the minimum wage or a wage determined by bargaining (see below). As discussed below, the latter is increasing in $a$, but less than one for one. Consequently, firm flow profits, $a d-w^{1}(a)$, are increasing in $a$. The term $\beta\left(\int_{a_{\min }}^{a_{\max }} \max \left[\tilde{W}^{F, 1}(z), \tilde{V}-f\right] d F(z)\right)$ is the discounted firm value of the contact to the worker in the beginning of the following period, consisting of the expected value of the firm value of a match with future idiosyncratic productivity $z, \tilde{W}^{F, 1}(z)$, and the firm value if separation takes place, $\tilde{V}-f$. This separation firm value is in turn the difference between the value of a vacancy and firing costs, $f$, which are assumed to accrue to the firm in case of separation. For the following exposition, it will be useful to define $W^{F, 1}(a)=\tilde{W}^{F, 1}(a)-(\tilde{V}-f)$, the quasi rent

12 The case that a worker desires separation wheres the firm does not will not occur in this model. The reverse scenario, however, can occur when the minimum wage is binding. Hence, we assume that the separation decision is always made by the firm. 
of a match accruing to the firm, i. e. the difference between the firm's match value and its outside option.

Free entry is assumed for vacancy creation, implying $\tilde{V}=0$. Using this equilibrium condition and the above definition, we have

$$
W^{F, 1}(a)=a d-w^{1}(a)+f+\beta\left(\int_{a_{\min }}^{a_{\max }} \max \left[W^{F, 1}(z), 0\right] d F(z)-f\right) .
$$

Because $W^{F, 1}(a)$ is increasing in $a$ and continuous, there is a value $R^{1}$ such that $W^{F, 1}\left(R^{1}\right)=0$ and $W^{F, 1}(z)>0\left(W^{F, 1}(z)<0\right)$ for all $z>R^{1}\left(z<R^{1}\right)$. Hence, $\int_{a_{\min }}^{a_{\max }} \max \left[W^{F, 1}(z), 0\right] d F(z)=\int_{R^{1}}^{a_{\max }} W^{F, 1}(z) d F(z)$ and

$$
W^{F, 1}(a)=a d-w^{1}(a)+f+\beta\left(\bar{W}^{F, 1}-f\right)
$$

where $\bar{W}^{F, 1}=\int_{R^{1}}^{a_{\max }} W^{F, 1}(z) d F(z) \cdot \bar{W}^{F, 1}$ is the expected quasi rent accruing to the firm in the following period.

$R^{1}$ and hence the separation rate $F\left(R^{1}\right)$ are determined by the condition $W^{F, 1}\left(R^{1}\right)=0$, i. e.

$$
0=R^{1} d-w^{1}\left(R^{1}\right)+f+\beta\left(\bar{W}^{F, 1}-f\right) .
$$

The separation rate is negatively affected by firing costs and by the firm's expected future quasi rent of a match. For the case of a binding minimum wage, the level of this wage will directly positively affect the separation rate.

The assumption of free entry for vacancy creation implies

$$
0=-\kappa+\frac{M(S U, V)}{V} \beta \int_{a_{\min }}^{a_{\max }} \max \left[W^{F, 0}(z), 0\right] d F(z),
$$

where $\kappa>0$ represent flow vacancy posting costs, $\frac{M(S U, V)}{V}$ is the probability that the vacancy makes a contact to a searching worker, and $\beta \int_{a_{\min }}^{a_{\max }} \max \left[W^{F, 0}\right.$ $(z), 0] d F(z)$ is the discounted quasi-rent accruing to the firm if a contact is made. This firm quasi-rent in turn satisfies

$$
W^{F, 0}(a)=a d-w^{0}(a)+\beta\left(\bar{W}^{F, 1}-f\right)
$$

Note that next period's quasi rent is indexed by 1 , indicating the transition form initial match to a pre-existing match. The reason for this distinction is that initial matches are assumed not to be subject to firing costs. For the same reason, there will be a distinction between wages $w^{0}(a)$ and $w^{1}(a)$. 
Initial contacts between a searching worker and a vacancy only become matches when $a>R^{0}$, i.e. with probability $1-F\left(R^{0}\right)$, where this threshold productivity $R^{0}$ is determined by

$$
0=R^{0} d-w^{0}\left(R^{0}\right)+\beta\left(\bar{W}^{F, 1}-f\right)
$$

Using the definition $\bar{W}^{F, 0}=\int_{R^{0}}^{a_{\max }} W^{F, 0}(z) d F(z)$, the free entry condition can be written as

$$
\kappa=\frac{M(S U, V)}{V} \beta \bar{W}^{F, 0} .
$$

Equation (30) determines the number of vacancies posted in equilibrium. Together with $\left(1-F\left(R^{0}\right)\right)$ and workers' search intensity, the the number of vacancies in turn determines the job finding rate.

\subsubsection{Search Intensity}

The worker value of being matched to a firm satisfies, in units of the final good,

$$
\tilde{W}^{H, j}(a)=w^{j}(a)-\frac{\mathcal{D}(N)}{\mathcal{U}_{C}}+\beta \int_{R^{1}}^{a_{\max }} \tilde{W}^{H, 1}(z) d F(z)+\beta F\left(R^{1}\right) \tilde{U},
$$

for 'new' and 'pre-existing' matches $(j=0$ and $j=1)$, respectively. The worker receives wage $w^{j}(a) . \mathcal{D}(N)$ denotes disutility costs of working, which may depend on household employment $N . \mathcal{U}_{C}$, denotes the marginal utility of consumption. ${ }^{13}$ The term $\beta \int_{R^{1}}^{a_{\max }} \tilde{W}^{H, 1}(z) d F(z)$ represents the discounted expected value of being employed in the following period. If separation takes place in the following period, the worker enters the pool of searching workers, which occurs with probability $F\left(R^{1}\right)$ and yields associated value $\tilde{U}$. This value of searching in turn satisfies

$$
\begin{array}{r}
\tilde{U}=w^{u}-\frac{\mathcal{S}(S)}{\mathcal{U}_{C}}+\beta p S\left[\int_{R^{1}}^{a_{\max }} \tilde{W}^{H, 0}(z) d F(z)+F\left(R^{0}\right) \tilde{U}\right] \\
+\beta(1-p S) \tilde{U} .
\end{array}
$$

Here, we assume that a searching worker receives unemployment benefits $w^{u}$. The term $\mathcal{S}(S)$ represents search effort costs, denominated in utility, which may

13 As common in the literature, we assume a representative household, i. e. family insurance, such that marginal utility of consumption depends only on aggregate consumption. 
depend on search intensity. With probability $p=\frac{M(S U, V)}{S U}$, each unit of search intensity delivers a contact to a vacancy in the following period. This probability is exogenous from the perspective of the individual worker. The expected worker value of an initial contact to a vacancy is $\int_{R^{0}}^{a_{\max }} \tilde{W}^{H, 0}(z) d F(z)$. These contacts do no result in matches with probability $F\left(R^{0}\right)$. In this case, the worker remains searching, with value $\tilde{U}$. the same holds for the case that no contact is made, occurring with probability $1-p S$.

It is again helpful to represent the worker value of a match as a quasi rent, $W^{H, j}(a)=\tilde{W}^{H, j}(a)-\tilde{U}$, i. e. as the difference between the worker value of a match and the outside option of searching. This quasi rent satisfies

$$
W^{H, j}(a)=w^{j}(a)-w^{u}+\frac{\mathcal{S}(S)-\mathcal{D}(N)}{\mathcal{U}_{C}}-\beta p S \bar{W}^{H, 0} \cdot+\beta \bar{W}^{H, 1}
$$

For the value of searching, we have

$$
\tilde{U}=w^{u}-\frac{\mathcal{S}(S)}{\mathcal{U}_{C}}+\beta p S \bar{W}^{H, 0}+\beta \tilde{U},
$$

where $\bar{W}^{H, 0}=\int_{R^{0}}^{a_{\max }} \tilde{W}^{H, 0}(z) d F(z)$.

The following first order condition characterizes the choice of search intensity, and follows from the maximization of the worker value of searching:

$$
\frac{\mathcal{S}^{\prime}(S)}{\mathcal{U}_{C}}=\beta p \bar{W}^{H, 0}
$$

We assume that marginal utility costs of search intensity are increasing in searching intensity. Accordingly, search intensity is increasing in the probability of making a contact to a vacancy and the worker value of such a contact. It is decreasing in consumption, as this leads to a decrease in the marginal utility of consumption.

\subsubsection{Wage Determination}

The wage in an employment relationship of type $j$ with productivity $a$ is the maximum of the minimum wage $w^{\text {min }}$ and the bargained wage $w^{b, j}(a)$ :

$$
w^{j}=\min \left\{w^{\min }, w^{b, j}(a)\right\}
$$

As is common in the literature, the latter is determined via Nash bargaining, maximizing 


$$
\max _{w}\left(W^{H, j}(a)\right)^{\omega}\left(W^{F, j}(a)\right)^{1-\omega},
$$

with first order condition $\omega W^{F, j}(a)=(1-\omega) W^{H, j}(a)$ and solution for the bargained wage:

$$
\begin{aligned}
& w^{1, b}(a)=\omega(a d+(1-\beta) f)+(1-\omega)\left(w_{u}-\frac{\mathcal{S}(S)-\mathcal{D}(N)}{\mathcal{U}_{C}}+\beta p S \bar{w}^{H, 0}\right) \\
& +\beta\left(\omega \bar{W}^{F, 1}-(1-\omega) \bar{W}_{N}^{H, 1}\right) \\
& w^{0, b}(a)=\omega(a d-\beta f)+(1-\omega)\left(w_{u}-\frac{\mathcal{S}(S)-\mathcal{D}(N)}{\mathcal{U}_{C}}+\beta p S \bar{w}^{H, 0}\right) \\
& +\beta\left(\omega \bar{W}^{F, 1}-(1-\omega) \bar{W}_{N}^{H, 1}\right) .
\end{aligned}
$$

The parameter $0<\omega<1$ is the weight of the workers' quasi rent in wage bargaining and can be interpreted as workers' bargaining power. Bargained wages are linearly increasing in match specific productivity and increasing in the value of workers' outside option. They are also increasing in the value of the disutility of work, denominated in units of the final good, $\frac{\mathcal{D}(N)}{\mathcal{U}_{C}}$. In the quantitative analysis of the model, a minimum wage is introduced that is binding on an interval of productivities $\left[R^{j}, Q^{j}\right]$, i. e. larger than the bargained wage on this interval. The minimum wage is than the actual wage paid in matches with productivities falling in this range. The threshold productivity $Q^{j}$ is determined by

$$
w^{\min }=w^{j, b}\left(Q^{j}\right)
$$

In the initial steady state analyzed below, there is no minimum wage. Hence, all wages are bargained wages and we have $0=\omega W^{F, 1}\left(R^{j}\right)=(1-\omega) W^{H, j}\left(R^{j}\right)$. This implies that the separation decision with bargained wages is not only privately efficient for the firm, but also from the worker's perspective. This is not the case when a binding minimum wage is introduced, because as $w^{\min }>w^{j, b}\left(R^{j}\right)$, $0=\omega W^{F, 1}\left(R^{j}\right)<(1-\omega) W^{H, j}\left(R^{j}\right)$. Hence the separation at productivities below $R^{j}$ is privately efficient from the perspective of the firm, but not the worker.

\subsubsection{Labor Market Equilibrium in Steady State}

For a given relative price of intermediate goods and for a given level of aggregate consumption, we can determine all labor market quantities using the above equilibrium conditions. The endogenous objects $\left\{R^{j}, Q^{j}, V, N, U, w^{j}, w^{b, j}, W^{H, j}, W^{F, j}, S\right\}$ satisfy (25), (26), (27), (28), (29),(30), (31), (32), (33), (34), (35), (36) and $U=1-N$. 


\subsubsection{Production, Capital Accumulation and General Equilibrium}

As in Section 2.1, capital stock, investment, and consumption satisfy the equilibrium conditions (3) and (4). Production and factor prices satisfy (9), (10) and (11), where

$$
g=\frac{\int_{R^{0}}^{a_{\max }} \operatorname{adF}(a)}{1-F\left(R^{0}\right)} \frac{N_{0}}{N}+\frac{\int_{R^{1}}^{a_{\max }} \operatorname{adF}(a)}{1-F\left(R^{1}\right)} \frac{N_{1}}{N} .
$$

The aggregate resource constraint is modified, due to the presence of vacancy and firing costs, with

$$
c=y-x-\kappa V-f F\left(R^{1}\right) N .
$$

The effects of introducing a binding minimum wage on equilibrium outcomes are too complex to analytically analyze. Hence, we turn to a quantitative analysis, providing intuition for the simulation results in Sections 3.3 and 3.4 . Subsequently, we analyze an extension of the model to two sectors, similarly to the extension discussed in Section 2.2.

\subsection{Calibration and Simulation Experiments}

The quantitative model experiments compare an initial steady state without a minimum wage to one with a minimum wage. Hence, only long-run implications are analyzed, i. e. after the capital stock and employment have fully adjusted. The calibration of model parameters is based on Joseph et al. (2004), with an adjustment of the targets with data from Germany where available. Because of considerable uncertainty about some parameter values, however, a sensitivity analysis is undertaken and the effect of the variation of important parameter values on the simulation results is discussed. Thus, the analysis delivers a range of outcomes for the effects of the introduction of minimum wages.

The length of a time period is set to one quarter. We fix functional forms for $\mathcal{S}(S)$ and $\mathcal{D}(N)$, as in Joseph et al. (2004), with

$$
\begin{gathered}
\mathcal{S}(S)=\sigma_{1} S^{\sigma_{2}} \\
\mathcal{D}(N)=\sigma_{3} N^{\sigma_{4}} .
\end{gathered}
$$

The parameters $\sigma_{2}$ and $\sigma_{4}$ are set directly, as discussed below. Note that both of these utility costs can be interpreted as stemming from a reduction in home production or leisure as search effort or hours worked are increased. The parameter 
$\sigma_{1}$ can be normalized to one. The parameter $\sigma_{3}$ and matching efficiency $\bar{m}$ are selected such that the model without minimum wages matches certain values for average unemployment duration and the separation rate (see below). The parameter $\sigma$ of the productivity distribution (see eq. 13) and the level of the minimum wage are selected to match targets for the minimum wage in relation to the wage distribution for Germany, as described in Section 2.1.5. The mean of the productivity distribution can be normalized to one. Parameters $f, w^{u}$ and $\kappa$ are targeted to certain values relative to the average wage in steady state without minimum wages:

$$
\bar{w}=\frac{\int_{R^{0}}^{a_{\max }} w^{0}(a) d F(a)}{1-F\left(R^{0}\right)} \frac{N_{0}}{N}+\frac{\int_{R^{1}}^{a_{\max }} w^{0}(a) d F(a)}{1-F\left(R^{1}\right)} \frac{N_{1}}{N} .
$$

Some parameters will be identical in all simulation experiments that we report, because their variation in plausible ranges did not significantly affect the results. These include paramters set as in Section 2.1.5: (i) the production elasticity of capital in the Cobb-Douglas production function, which is set to a value of $1 / 3$, (ii) the rate of depreciation on physical capital, set to 0.025 per quarter, and (iii) the discount factor in utility, set to 0.99 and implying a real rate of one percent per quarter. Furthermore, they include the following parameters or targets pertaining to the labor market, which we take from Joseph et al. (2004): The separation rate is set to 4 percent per quarter. In an application for Germany, Balleer et al. (2016) use a lower rate of 3 percent. Moreover, in some applications of the type of model used here, separations also occur for exogenous reasons. Balleer et al. (2016), for example, model and set the fraction of exogenous separations to 2/3. These variations in the level or nature of separations had no significant impact on the results. The elasticity of the matching function with respect to vacancies is set to 0.4, as in Joseph et al. (2004) and also in Balleer et al. (2016). A variation to 0.6 had no significant impact on the results. Vacancy costs $\kappa$ are set to 28 percent of the average wage. There is considerable uncertainty with respect to these costs, as there is no data for their direct measurement. A doubling or halving of this value had no significant effect on the results.

Six parameters / calibration targets remain to be set: average unemployment duration, the level of firing costs, the replacement rate of unemployment insurance benefits (both relative to the average wage), the bargaining power of workers, the parameter regulating the increase of disutility with increasing search effort, and the parameter regulating the increase in the disutility of work with employment. For these parameters / targets, a total of nine constellations are analyzed, corresponding to the labels of columns in Table 2: The baseline constellation with values set as in Joseph et al. (2004) in column (1), six constellations 
Table 2: One sector search model: parameter constellations.

\begin{tabular}{lrllllllll}
\hline Parameters / Calibration Targets & (1) & (2) & (3) & (4) & (5) & (6) & (7) & (8) & (9) \\
\hline avg. unemp. dur. (in quarters) $(\bar{m})$ & 2.4 & & 3.0 & & & & & & 3.0 \\
replacement rate $\left(w^{u} / \bar{w}\right)$ & 0.43 & & & & 0.65 & & & & 0.65 \\
firing costs $(f / \bar{w})$ & 0.7 & & & 1 & & & & 1 & \\
search intensity costs $\left(\sigma_{2}\right)$ & 2 & & & & & 1 & & 1 & \\
disutility of work $\left(\sigma_{4}\right)$ & 1 & & & & & & 2 & 2 & \\
bargaining power workers $(\omega)$ & 0.6 & 0.4 & & & & & & 0.4 & \\
\hline
\end{tabular}

varying a single parameter value to a plausible alternative value (while setting the other parameters to their baseline values), and two joint variations of all parameters to the combination of values previously analyzed that deliver the lowest (8) and highest (9) impact of minimum wages on employment, respectively. A quantitative feature of the model is that the level of unemployment is very sensitive to the replacements rate. The local (no minimum wage) semielasticity of unemployment with respect to the replacement rate in the baseline constellation (1), for example, is around 6 and thus double the value of 3 estimated in Costain and Reiter (2008). Constellation (8), which delivers the lowest impact of the minimum wage introduction on unemloyment (see below), is also the one that generates the lowest value for this semielasticity, with a value of around 4, and thus closer to their estimate.

\subsection{Simulation Results}

Simulation results are reported in Table 3, with columns corresponding to parameter constellations in Table 2.

For the baseline constellation in column (1), results show a large long-run increase in the unemployment rate of 6 percentage points. This corresponds to a large reduction in employment by 6.6 percent, i. e. a slightly larger reduction than in the previously analyzed neoclassic model. This is remarkable, as one might suspect that search frictions, by partially detaching wages from workers' marginal product, leave room for wage increases and thereby lead to the destruction of fewer employment relationships. The unemployment rate is determined by separation and job finding rates. The separation rate increases by 3.2 percentage points, i. e. doubling of its value starting from an initial 3 percent, while the job finding rate decreases only slightly. As described above, the increase in the separation rate follows because matches with low productivity are not profitable for firms after the introduction of the minimum wage. Note that the increase of 3.2 percent 


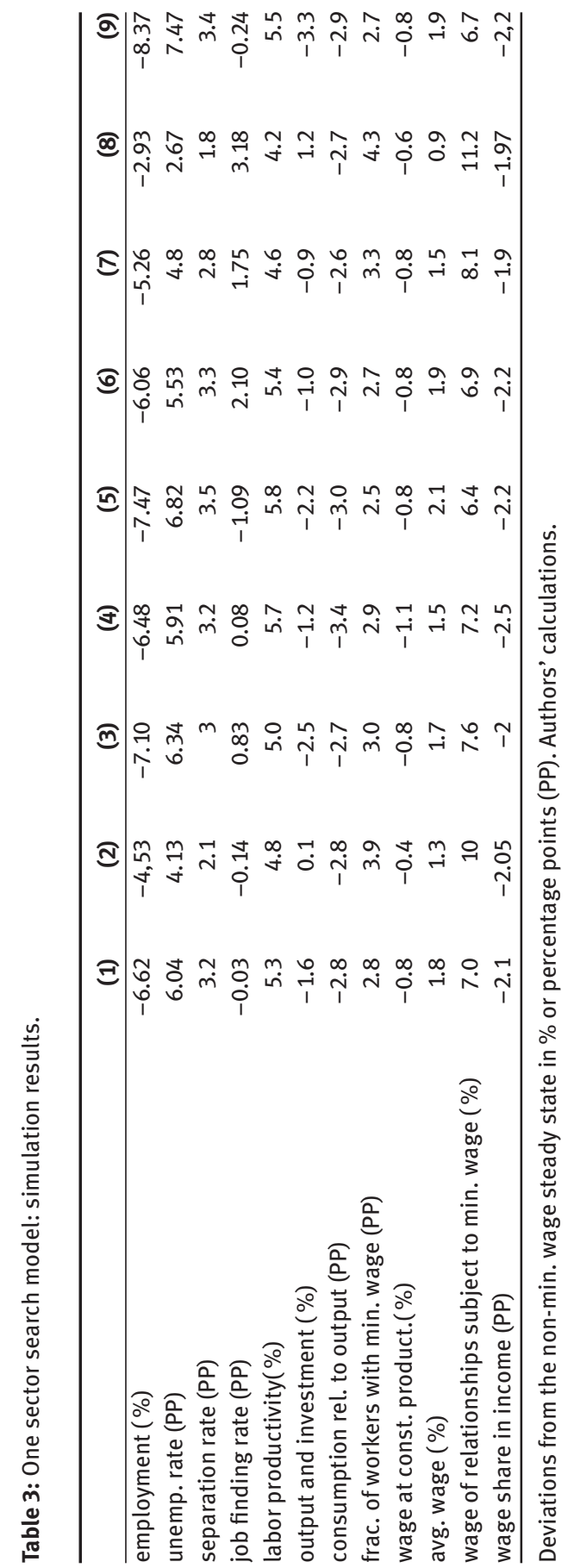


is smaller than the 6 percent of wages and hence employment relationships which fall below the value of the minimum wage in the initial steady state, as implemented in the calibration. Consequently, it is true that the search frictions leave room for wage increases that mitigate job destruction. But the same search frictions imply that it takes time for separated workers to find new employment relationships, via a job finding rate that is less than one. Two countervailing effects influence the job finding rate: First, - in all simulation experiments analyzed here - search intensity and even vacancy creation increase after the introduction of the minimum wage, leading to an increase in the rate of initial contacts made. Search intensity increases because a decrease in consumption (see below) makes finding a job much more valuable to workers. Vacancy creation increases because average wage costs of firms decrease relative to average labor productivity, due to a deterioration of workers' bargaining position (see below). However, the introduction of the minimum wage also increases the productivity threshold required for contacts to be profitable for firms, in turn decreasing the fraction of contacts which lead to an employment relationship. In the current parameter constellation, this latter negative effect on the job finding rate dominates.

Average labor productivity increases, as in the simple neoclassic model, here by 5.3 percent, because matches with low productivity are no longer formed and there is a shift to higher productivity employment. The increase in labor productivity only partly offsets the decrease in employment, however, as total output and investment (which is proportional to output in steady state) decrease by 1.6 percent. Consumption relative to output decreases by 2.8 percentage points, due to a strong increase in vacancy and firing costs in response to the introduction of the minimum wage, which crowd out consumption. The strong reduction in consumption in turn implies a deterioration of the bargaining position of workers, leading to reduction in bargained wages and a negative spillover effect of minimum wages: The average wage of employment relationships with a level of productivity that makes them profitable before and after the introduction of the minimum wage (wage at const. product. in Table 3) decreases by 0.8 percent. This decrease c.p. also implies that more vacancies are created, overcompensating the negative effects of the minimum wage on vacancy creation through higher wages in the region of productivities where the minimum wage is binding, the increased destruction of low productivity matches, and the associated increase in firing costs.

The overall average wage increases by 1.8 percent, largely due to the fact that low productivity and hence low wage jobs are destroyed. The fraction of workers that receive the minimum wage is 2.8 percent. The average wage of these workers is 7.0 percent higher than wages at employment relationships with the same productivity before the introduction of minimum wages (wage of relationships 
affected by min. wage in Table 3). Because the increase in the overall average wage is smaller than the decrease in employment, wage income falls. The share of wages in total income falls by 2.1 percentage points, indicating that the expenditures on firing in vacancy costs increase, as the income share of capital remains constant due to the assumptions on technology. The residual income (after subtraction of wage and capital income) flows to firms, and - due to the free entry condition - compensates these for vacancy and firing costs.

There is considerable uncertainty regarding many of the parameter values and calibration targets in this exercise. For this reason, we now vary parameters one at a time to assess the sensitivity of results.

\subsubsection{Bargaining Power}

In the literature, a value of 0.5 is often used for the bargaining power of workers, associated with an equal sharing of the match surplus between firm and worker. Another value commonly used in the literature follows from the so-called Hosios condition (Hosios 1990), which under certain conditions yields an efficient market outcome. Here the parameter is set to the respective elasticity in the matching function. The value chosen by Joseph et al. (2004) follows this logic, setting a value of 0.6. In Column (2) in Tables 2 and 3, the bargaining power of workers is lowered to 0.4 , leading ceteris paribus to a lower bargained wage. In this experiment, the introduction of the minimum wage leads to an increase of the unemployment rate by only 4.2 percentage points. This to a large extent reflects a considerably smaller increase of the separation rate of 2.1 percentage points, much smaller than in the baseline. The effect of the reduction in workers' bargaining share on unemployment generated by the minimum wage introduction is considerable. A further reduction to 0.3 implies an increase in the unemployment rate of only 3.2 percentage points.

The reduction of workers' bargaining share can be interpreted as increasing labor market power of firms. It is well known that models with monopsonistic firms can generate employment gains of minimum wages due to increasing labor supply. A similar mechanism is present in the model here via endogenous search intensity: When workers' bargaining share is low, the introduction of a minimum wage has the potential to substantially increase the returns to job search and thus the job finding probability. However, the mechanism quantitatively responsible for the mitigation of employment losses in the model as calibrated here is different: Because the firm share in the surplus is now larger, there is more leeway at a given productivity to pay a minimum wage above the bargained wage without implying negative firm profitability of the match. Output and investment 
even increase slightly in this scenario and wages at employment relationships subject to the minimum wage increase considerably. The effects on the remaining quantities are not significantly different from the baseline scenario.

\subsubsection{Unemployment Duration}

Joseph et al. (2004) use a calibration target of 2.4 quarters for the average unemployment duration. Balleer et al. (2016), using data for Germany, derive a calibration target of 3 quarters. Using this latter target in Column (3), the introduction of the minimum wage leads to a slightly larger increase in unemployment of 6.3 percentage points. The job finding rate even increases, but this increase does not compensate the effect of the increase in the separation rate. The stronger decrease in employment in turn leads to a stronger reduction in production and investment. The effects for the remaining quantities remain relatively unchanged.

\subsubsection{Firing Costs}

For firing costs, Joseph et al. (2004) use a value of 70 percent relative to the average wage. In the experiment of column (4), these costs are raised to 100 percent of the average wage. Despite this increase, the rise is unemployment is only slightly smaller than in column (1). Consumption and wages relative to output respond more strongly, other quantities are not significantly affected.

\subsubsection{Replacement Rate}

Unemployment insurance policy in Germany suggests a value for the replacement rate of 0.65 instead of 0.43 . This leads in Column (5) to a stronger effect on the unemployment rate, which now increases by 6.8 percentage points, induced by a stronger reaction of the separation rate. Because higher unemployment benefits raise the outside option value of workers, the total surplus of a match decreases and thus also the scope for wage increases that do not lead to a separation. This effect also negatively influences the job finding rate. The contact rate increases, as in the baseline of Column (1), but a smaller fraction of these contacts is productive enough to form a match. The reduction in output is stronger due to the larger decrease in employment and similarly for consumption relative to output, due to increased firing costs. 


\subsubsection{Search Costs}

The baseline parameter constellation assumes an elasticity of search costs with respect to search intensity of 2. In the experiment of column (6), this parameter value is reduced to 1 . Hence, search intensity will react more strongly to the difference between the worker value of being employed and the value of searching. Accordingly, the increase in unemployment is smaller in this experiment, driven by a strong increase in the job finding rate induced by a large increase in search effort.

\subsubsection{Disutility of Working}

The elasticity of disutility costs of working with respect to employment is set to 1 in the baseline. This implies that the utility loss associated with a marginal increase in employment is constant. Although this is plausible, it may well be the case that the marginal disutility is increasing in employment, perhaps due to decreasing marginal productivity in home production. In the experiment reported in Column (7), this elasticity is instead set to 2 . The resulting increase in unemployment of 4.8 percentage points is much smaller than in the baseline. The reason is that the value of searching now decreases more strongly with falling employment. Hence the surplus value of an employment relationship increases more strongly, which in turn implies a smaller increase in the separation rate and an increase in the job finding rate in response to the introduction of the minimum wage. The reductions in output and consumption relative to output are also smaller. The latter results from an attenuated increase in firing costs.

\subsubsection{Joint Variation of Parameters}

With these experiments in mind, we constructed two additional parameter constellations. For the first (Column 8), we pick those parameter values from the previous experiments that separately deliver the smallest decrease in employment. Hence, in deviation from the baseline constellation, the elasticities of the disutility of work and search costs are set to 2 and 1, respectively, firing costs are set to 100 percent of the wage, and the bargaining power is set to 0.4 . Under this constellation, unemployment increases by only 2.7 percentage points. Production increases by 1.1 percent, whereas decreases in consumption and wages relative to output are similar to those in the baseline. The fraction of workers receiving 
the minimum wage is now 4.3 percent, significantly higher than in the baseline. The separation rate increases by only 1.8 percentage points and the job finding rate increases by 3.2 percentage points, implying a decrease in unemployment duration.

For the second parameter constellation (Column 9), we pick those parameter values associated with the largest decrease in employment. Unemployment duration was set to 3 quarters and the replacement rate to 65 percent. Here the unemployment rate increases strongly, by 7.5 percentage points, and output falls by 3.3 percent. In contrast to the previous experiment, the job finding rate decreases, by 0.24 percentage points. Note that the effects of consumption and wages relative to output do not differ strongly between these two experiments.

\subsection{Discussion}

From the above model experiments, the following conclusions can be drawn concerning the effects of the minimum wage introduction in this model environment:

(1) The employment effects are consistently strongly negative and are driven by an increase in the separation rate. This increase accounts for more than 95 percent of the increase in the unemployment rate in all constellations considered. Note that the calibration target for the minimum wage level was that 6 percent of workers earn a wage less than or equal to this level before its introduction. The increase in separations is clearly less than these 6 percent, because the quasi rent accruing to employment relationships allows for wage increases in some range. If all separated workers would re-enter employment in the following period, the increase in the unemployment rate would mirror the increase in the separation rate. Because the process of finding a new job takes time, however, the increases in the unemployment rate is larger than the increase in the separation rate.

(2) Labor productivity increases in all experiments, between 4.2 and 5.8 percent. This increase and the reduction in employment have opposite effects on production and the sign of the overall effect on production is ambiguous, with a range of simulation results between +1.1 to -3.3 percent. But in all experiments, the levels of consumption and wage income fall. The introduction of the minimum wage increases churning in the labor market due to increased separation of low productivity jobs. This goes hand in hand with increased expenditures on vacancy and firing costs, which - given a constant proportion of capital expenditures and capital income in steady state - crowd out consumption and labor income.

(3) Search intensity increases in all experiments, but this increase is not strong enough to induce positive employment effects of the minimum wage. Flinn 
(2006)'s related analysis for the US yields positive employment effects of minimum wage increases for certain parameter constellations. In his partial equilibrium model with endogenous labor force participation and exogenous contact rates, a minimum wage increase results in an increase in employment, along with an increase in unemployment. Endogenizing contact rates, minimum wages reduce employment for relevant levels of minimum wages (Flinn 2006). We use a general equilibrium model with endogenous contact rates as firms adjust vacancies given the introduction of a minimum wage. The decrease in employment therefore is well in line with the relevant literature.

(4) The effect on the the job finding rate and hence unemployment duration is ambiguous. The increase in search intensity would by itself lead to an increase in the job finding rate. At the same time, however, the productivity cutoff required for contacts to lead to matches increases, reducing the job finding rate. Furthermore, vacancy creation influences the job finding rate. In all constellations we have considered, the firm value of an employment relationship increases. This leads to increased vacancy creation and positively affects the job finding rate. The reason for the increase in the firm value is a reduction of bargained wages, which is in turn induced by a strongly negative reaction of workers' outside option. In part, the latter can be attributed to a strong reduction in consumption, which decreases the utility costs of employment. To further understand this channel, we alternatively modeled these costs as constant in units of output. Under this alternative assumption, the firm value decreases in all constellations, with negative effects on the job finding rate through reduced vacancy creation. In the baseline parameter constellation, for example, the unemployment rate rose by 7.48 percentage points, i. e. the negative employment effect of the minimum wage was stronger, and this was to a large extent driven by a reduction in the job finding rate by 2.2 percentage points. Bargained wages also decreased in this scenario, again due to the decrease in workers outside option, which is now driven by the reduction in the job finding rate.

(5) The proportion of workers receiving the minimum wage after its introduction lies between 2.5 and 4.3 percent and hence well below the 6 percent of workers receiving this wage level or less before its introduction, due to increases in separations. Average wages increase in all experiments by between 0.9 and 2.1 percent, driven by increased productivity requirements. The bargained wage at given productivity fell in all experiments, by between 0.4 and 1.0 percent, due to the decrease in workers' outside option. Wages for employment relationships earning less than the minimum wage before its introduction instead increase by between 6.7 and 11.2 percent. 
In sum, the simulation experiments point to employment effects that do not substantially differ from those found using the simple neoclassic model in Section 2.3. Although additional mechanisms such as search intensity (or labor force participation) may play a quantitatively significant role, these require further analysis, in particular in conjunction with the quantitatively important effect of minimum wages on separations found in the model. In the context of the present model, evidence on the semielasticity of unemployment w.r.t to the replacement rate (such as Costain and Reiter (2008)) can provide additional information on which of the analyzed parameter constellations should be preferred. Constellation (8) yields a semilesticity closest to this estimate and implies employment effects that are about half as large as those found in the simple neoclassical model.

\subsection{Two-Sector Extension}

In the one sector model above, each employment relationship is potentially subject to the minimum wage via idiosyncratic productivity shocks. In reality, however, persistent wage differences are observed and only a limited number of relationships are deemed to be potentially affected by minimum wages. At the same time, the aggregate one sector model abstracts from changes in product prices, because only one homogenous (intermediate) good is produced. In reality, increased costs due to minimum wages could be passed on in terms of higher prices, changing the relative price between goods whose cost structure is affected by minimum wages and those whose costs remain unaffected.

To address these concerns, we extend the search model to a two sector environment analogously to Section 2.2. For simplicity and to facilitate a straightforward comparison with previous results, we assume that no frictions are present in a high skilled sector where the minimum wage is not binding. The latter is guaranteed by the parametrization in the quantitative experiments below. The determination of employment in this sector hence follows 2.2. The minimum wage is relevant for a low skilled sector, however, modeled as in Section 3.1, where $d^{L}$ replaces $d$ as the relative price of intermediate goods produced in that sector. Calibration follows 3.2 and the production structure of aggregate output is modeled and calibrated as in 2.2.

We use the model to quantitatively assess the introduction of minimum wages for three parameter constellations. These correspond to columns (1), (8) and (9) of Table 2, i. e. the baseline calibration of Joseph et al. (2004), a parametrization with small employment effects and one with large effects. Table 4 displays the simulation results. 
Table 4: Two sector search model: simulation results.

\begin{tabular}{lrrr}
\hline & (1) & (8) & (9) \\
\hline employment (\%) & -3.20 & -2.36 & -3.21 \\
unemp. rate (PP) & 3.11 & 2.32 & 3.13 \\
separation rate, low-skilled (PP) & 13.0 & 11.7 & 13.1 \\
job finding rate, low-skilled (PP) & 8,3 & 14.9 & 10.8 \\
labor productivity(\%) & 2.4 & 2.2 & 2.3 \\
output and investment (\%) & -0.9 & -0.2 & -1.0 \\
consumption rel. to output (PP) & -0.5 & -0.6 & -0.5 \\
frac. of workers with min. wage (PP) & 1.9 & 4.1 & 1.9 \\
avg. wage (\%) & 1.6 & 1.3 & 1.6 \\
avg. wage, high-skilled (\%) & -0.9 & -0.2 & -1.1 \\
avg. wage, low-skilled (\%) & 12.6 & 4.1 & 12.9 \\
wage, low-skilled, at const. product.(\%) & 8.7 & 0.5 & 9.2 \\
wage of relationships subject to min. wage (\%) & 14.5 & 9.1 & 15.3 \\
wage share in income (PP) & -0.5 & -0.6 & -0.5 \\
\hline
\end{tabular}

Deviations from the non-min. wage steady state in \% or percentage points (PP).

Authors' calculations.

Note that in all experiments, the increase in the overall unemployment rate is much smaller than in the one sector model, between 2.3 and 3.1 percentage points. For low-skilled workers however, this rate increases by between 12.2 and 17.2 percentage points. The reason for the muted increase in overall unemployment is an increase of the relative price of goods produced in the low-skilled sector, with increases across simulation experiments between 1.5 and 7.5 percent. Wages in the high-skilled sector fall by between 0.2 and 1.1 percent, in response to the decrease in the relative price of goods produced in this sector.

Wages of low-skilled workers increase by between 4.1 and 12.9 percent. Here, it is noteworthy that - in contrast to the one-sector model - wages also increase for those productivity levels that involve production before and after the introduction of minimum wages (wage, low-skilled, at const. product. in Table 4), by between 0.5 and 9.2 percent. Hence, in contrast to the one-sector model, the increase in average wages is not mechanically due to increased labor productivity alone. In parameter constellation (8), wages of those relationships not subject to a binding minimum wage fall, as observed in all constellations analyzed for the one-sector model. In the other two constellations, however, wages in these relationships also rise, a positive spillover effect induced by the relative price increase.

Furthermore, note that the job finding rate rises considerably in all parameter constellations, again induced by the relative price increase. Increases in unemployment are hence solely due to increases in the separation rate. 
The reduction in output and investment is also attenuated and falls between 0.2 and 1.0 percent. Effects on consumption and wages relative to income are also smaller than in the one-sector model. In sum, these simulation results point to the importance of relative price changes, that allow a pass-through of higher wage costs and may significantly mitigate the impact of minimum wages.

\section{Conclusion}

We analyze the introduction of a minimum wage in a structural model geared to quantitatively assess the long-run effects of the minimum wage introduced in Germany in 2015. The starting point is a simple general equilibrium model, where wages equal marginal products and the introduction of a binding minimum wage leads to unemployment for all workers whose marginal product falls below this wage floor.

In the first extension, a two-sector model is formulated, where a high skilled sector is not subject to minimum wages due to the high wages prevalent there. This extension is used to assess the importance of relative price changes between goods whose cost structure is affected by minimum wages and those whose cost structure is not affected.

In the second extension, the model is modified to allow for search and matching frictions, as these may play an important role in the functioning of the labor market and its response to policy changes. Again the effect of the introduction of a minimum wage as implemented in Germany is quantitatively analyzed both in a one-sector and in a two-sector environment, and for different plausible parameter constellations.

(1) The introduction of the minimum wage has strong negative employment effects in all model variants. Even considering different plausible parameter constellations, we do not find positive employment effects, which could in principle arise in the setting with search and matching frictions, as in Flinn (2006) for the US, for example. The link between the marginal revenue product of workers and their wage remains strong, also in the search and matching model with endogenous separations considered here. Hence, low productivity jobs become unprofitable for firms and are destroyed when a binding minimum wage is introduced. This separation effect dominates in explaining the large response of employment. Changes in job creation play a much smaller role and the sign of the effect of minimum wages on vacancy creation and the job finding rate of unemployed workers is not clear. Similarly, although negative effects on aggregate consumption are pronounced 
in all variants considered, the effect on output is less clear. In the search and matching environment, the introduction of the minimum wage leads to increased churning in the labor market, which on the one hand leads to higher average labor productivity and may increase output, compensating disemployment effects. On the other hand, the same increase in churning requires additional resources due to labor market frictions, which are then not available for consumption.

(2) Relative price changes between sectors differentially affected by the minimum wage play a potentially important quantitative role. If the cost structure of goods is asymmetrically affected by minimum wages, relative prices of heavily affected goods increase and substantially mitigate the long run employment effects.

(3) Other labor market policies and institutions may play a significant role in how the minimum wage policy affects labor market outcomes. In the simulation experiment involving an increase in the replacement rate of unemployment benefits, for example, the disemployment effects were significantly more pronounced. Similarly, policies that influence search intensity of unemployed workers may significantly alter the employment effects.

Taken together, the results highlight the multiple channels through which minimum wage policy affects outcomes and point to the role of the parametrization both for the direction and magnitude of the effects. Differences between these model implications and empirical evidence can inform the further development of models capable of delivering a counterfactual analysis and thus guidance in setting future minimum wage levels. Because all model variants remain highly stylized, their use for a quantitative counterfactual analysis is limited. However, in our view, they yield quantitative insights on the importance of different mechanisms and channels through which minimum wages affect outcomes in the long run.

In the search and matching model implemented above, for example, large increases in the separation rate are the driving force behind large disemployment effects found in the simulation experiments. Bossler and Gerner (2016) find evidence for an increase in separations in the wake of the minimum wage implementation in Germany, albeit a quantitatively small effect. There is, however, other empirical evidence that the separation rate instead falls in response to minimum wage increases (Portugal/Cardoso 2006; Dube et al. 2016; Liu et al. 2016; Gittings/Schmutte 2016; Hirsch et al. 2015). This suggests that the mechanisms underlying the separation of employment relationships should be analyzed more closely. In the model, for example, separations are solely due to firms' 
firing decisions (layoffs), whereas quits and job-to-job transitions of workers are ignored. A minimum wage may well influence this latter component of overall separations.

Furthermore, the simulation results entail negative spillovers of minimum wages on the bargained wages of workers not directly affected by the wage floor. However, from a theoretical, experimental, and empirical perspective, positive spillovers are likely, even on sectors not directly affected by the policy (lighthouse effects). Methodologically, extensions of the model should integrate and analyze the role of fairness (Green/Harrison 2010; Falk et al. 2006; Dittrich et al. 2011) and explore other mechanisms for the employment decision (Brown et al. 2014, 2015) and for wage setting (Burdett/Mortensen 1998; Flinn et al. 2017). A further extension could involve the inclusion of a participation margin, similarly to Flinn (2006), which may significantly mitigate the disemployment effects found here.

\section{References}

Adjemian, S., H. Bastani, M. Juillard, F. Karame, J. Maih, F. Mihoubi, G. Perendia, J. Pfeifer, M. Ratto, S. Villemot (2011), Dynare: Reference Manual, Version 4, Dynare Working Papers, 1 , CEPREMAP.

Ahlfeldt, G.M., D. Roth, T. Seidel (2018), The Regional Effects of Germany's National Minimum Wage. Economics Letters 172: 127-130.

Allegretto, S., A. Dube, M. Reich, B. Zipperer (2017), Credible Research Designs for Minimum Wage Studies: A Response to Neumark, Salas, and Wascher. ILR Review 70 (3): 559-592.

Bachmann, R., H. Frings (2017), Monopsonistic Competition, Low-Wage Labour Markets, and Minimum Wages-An Empirical Analysis. Applied Economics 49 (51): 5268-5286.

Balleer, A., B. Gehrke, W. Lechthaler, C. Merkl (2016), Does short-time work save jobs? A business cycle analysis. European Economic Review 84: 99-122. European Labor Market Issues.

Bils, M., P. Klenow (2004), Some Evidence on the Importance of Sticky Prices. Journal of Political Economy 112 (5): 947-985.

BMWI (2014), Soziale marktwirtschaft heute-impulse für wachstum und zusammenhalt. Jahreswirtschaftsbericht, Bundesministerium für Wirtschaft und Energie.

Bossler, M., H.-D. Gerner (2016), Employment Effects of the New German Minimum Wage: Evidence from Establishment-Level Micro Data. Technical report, IAB-Discussion Paper.

Brown, A., C. Merkl, D. Snower (2015), An Incentive Theory of Matching. Macroeconomic Dynamics 19 (3): 643-668.

Brown, A. J., C. Merkl, D. J. Snower (2014), The Minimum Wage from a Two-Sided Perspective. Economics Letters 124 (3): 389-391.

Burdett, K., D. T. Mortensen (1998), Wage Differentials, Employer Size, and Unemployment. International Economic Review 39 (2): 257-273.

Costain, J. S., M. Reiter (2008), Business Cycles, Unemployment Insurance, and the Calibration of Matching Models. Journal of Economic Dynamics and Control 32 (4): 1120-1155. 
Dhyne, E., L. J. Alvarez, H. Le Bihan, G. Veronese, D. Dias, J. Hoffmann, N. Jonker, P. Lunnemann, F. Rumler, J. Vilmunen (2006), Price Changes in the Euro Area and the United States: Some Facts from Individual Consumer Price Data. Journal of Economic Perspectives 20 (2): 171-192.

Dittrich, M., A. Knabe, K. Leipold (2011), Spillover Effects of Minimum Wages: Theory and Experimental Evidence. Working Paper 3576, CESifo.

Dube, A., T. W. Lester, M. Reich (2010), Minimum Wage Effects Across State Borders: Estimates Using Contiguous Counties. The Review of Economics and Statistics 92 (4): 945-964.

Dube, A., T. W. Lester, M. Reich (2016), Minimum Wage Shocks, Employment Flows, and Labor Market Frictions. Journal of Labor Economics 34 (3): 663-704.

Falk, A., E. Fehr, C. Zehnder (2006), Fairness Perceptions and Reservation Wages-the Behavioral Effects of Minimum Wage Laws. The Quarterly Journal of Economics 121 (4): 1347-1381.

Flinn, C., A. Gemici, S. Laufer (2017), Search, Matching and Training. Review of Economic Dynamics 25: 260-297. Special Issue on Human Capital and Inequality.

Flinn, C. J. (2006), Minimum Wage Effects on Labor Market Outcomes Under Search, Matching, and Endogenous Contact Rates. Econometrica 74 (4): 1013-1062.

Garloff, A. (2016), Side Effects of the New German Minimum Wage on (Un-) employment: First Evidence from Regional Data. Technical report, IAB-Discussion Paper.

Gemeinschaftsdiagnose, P. (2014), Deutsche konjunktur im aufschwung-aber gegenwind von der wirtschaftspolitik.

Gittings, R. K., I. M. Schmutte (2016), Getting Handcuffs on an Octopus: Minimum Wages, Employment, and Turnover. ILR Review 69 (5): 1133-1170.

Green, D. A., K. Harrison (2010), Minimum Wage Setting and Standards of Fairness. Technical report, IFS working papers.

Hirsch, B., T. Schank, C. Schnabel (2010), Differences in Labor Supply to Monopsonistic Firms and the Gender Pay Gap: An Empirical Analysis Using Linked Employer-Employee Data from Germany. Journal of Labor Economics 28 (2): 291-330.

Hirsch, B. T., B. E. Kaufman, T. Zelenska (2015), Minimum Wage Channels of Adjustment. Industrial Relations: A Journal of Economy and Society 54 (2): 199-239.

Hosios, A. J. (1990), On the Efficiency of Matching and Related Models of Search and Unemployment. The Review of Economic Studies 57 (2): 279-298.

Joseph, G., O. Pierrard, H. Sneessens (2004), Job Turnover, Unemployment and Labor Market Institutions. Labour Economics 11 (4): 451-468. European Association of Labour Economists 15th Annual Conference, Universidad Pablo de Olavide, Seville, 18-21 September 2003.

Knabe, A., R. Schöb, M. Thum (2014), Der flächendeckende Mindestlohn. Perspektiven der Wirtschaftspolitik 15 (2): 133-157.

Krause, M. U., H. Uhlig (2012), Transitions in the German Labor Market: Structure and Crisis. Journal of Monetary Economics 59 (1): 64-79. Carnegie-NYU-Rochester Conference Series on Public Policy at New York University on April 15-16, 2011.

Liu, S., T. J. Hyclak, K. Regmi (2016), Impact of the Minimum Wage on Youth Labor Markets. Labour 30 (1): 18-37.

Manning, A. (2003), Monopsony in Motion: Imperfect Competition in Labor Markets. Princeton University Press, New Jersey. 
Mindestlohnkommission (2016), Erster Bericht zu den Auswirkungen des gesetzlichen Mindestlohns. Bericht der Mindestlohnkommission an die Bundesregierung nach §9 Abs. 4 Mindestlohngesetz, Berlin.

Mortensen, D. T., C. A. Pissarides (1999), Chapter 18 Job Reallocation, Employment Fluctuations And Unemployment. PP. 1171-1228. in: John B. Taylor, Michael Woodford (eds.), Handbook of Macroeconomics, vol. 1. Elsevier, North-Holland, Amsterdam.

Neumark, D. (2017), The Employment Effects of Minimum Wages: Some Questions We Need to Answer. Technical report, National Bureau of Economic Research.

Neumark, D., J. I. Salas, W. Wascher (2014a), More on Recent Evidence on the Effects of Minimum Wages in the United States. IZA Journal of Labor policy 3 (1): 24.

Neumark, D., J. I. Salas, W. Wascher (2014b), Revisiting the Minimum Wage-Employment Debate: Throwing out the Baby with the Bathwater? ILR Review 67 (3_suppl): 608-648.

Portugal, P., A. R. Cardoso (2006), Disentangling the Minimum Wage Puzzle: An Analysis of Worker Accessions and Separations. Journal of the European Economic Association 4 (5): 988-1013.

Schmitz, S. (2017), The Effects of Germany's New Minimum Wage on Employment and Welfare Dependency. Discussion paper, Free University Berlin, School of Business \& Economics: Economics.

Statistisches Bundesamt (2016), 4 millionen jobs vom mindestlohn betroffen. Press release from 6.4.2016. last checked: 17.11.2017.

SVR (2013), Gegen eine rückwärtsgewandte Wirtschaftspolitik. Technical report, Sachverständigenrat zur Begutachtung der gesamtwirtschaftlichen Entwicklung. Jahresgutachten 2013/14. Wiesbaden.

Vom Berge, P., H. Frings (2017), High-Impact Minimum Wages and Heterogeneous Regions. Technical report, IZA Discussion Papers.

Article note: This article is part of the special issue "Effects of the Introduction of the Statutory Minimum Wage in Germany" published in the Journal of Economics and Statistics. Access to further articles of this special issue can be obtained at www.degruyter.com/journals/jbnst. 